\title{
My Personal Brand and My Web Presence: Mining Digital Footprints and Analyzing Personas in the World of IOT and Digital Citizenry
}

\author{
Fawzi BenMessaoud, Ph.D. \\ IU School of Informatics and \\ Computing, Indiana \\ University Purdue \\ University, Indianapolis \\ fawzbenm@iu.edu
}

\author{
Dwight William Hall \\ IU School of Informatics and \\ Computing, Indiana \\ University Purdue \\ University, Indianapolis \\ dwwhall@iu.edu
}

Holly Nichole Handlon

IU School of Informatics and

Computing, Indiana

University Purdue

University, Indianapolis

hhandlon@iu.edu

\author{
Taryn Elizabeth Husted \\ IU School of Informatics and Computing, \\ Indiana University Purdue University, \\ Indianapolis \\ thusted@iu.edu
}

\section{Niranjan Valmik Kshirsagar \\ IU School of Informatics and Computing, Indiana University Purdue University, Indianapolis nvkshirs@iu.edu}

Abstract-

Personal Branding is a way to elevate oneself in a new marketing concept. For many, building and managing a Personal Brand is about value, mission, image, and vision. However, with the shift in the marketplace and the rise of the Internet of Things (IoT), Personal Branding has become a data function and summation of one's Digital Footprint, which includes how people are seen by Databots and not just how they see themselves or others observe them. Subsequently, there has been an upsurge in the utilization of deep machine learning and predictive analytics to profile as well as select talents using their Personal Brand as a data function of their Web Presence/Digital Citizenry. To find a solution, a survey was conducted to examine the number of students who are not fully aware of their Web Presence/Digital Citizenry and how their social and professional networks can and will be used to profile them. After identifying this problem, the idea of building and managing a Personal Brand was explored. To solve this problem, a Personal Branding tool that allows students to develop and promote their Personal Brand using a Digital Passport to express, share, and manage a multidimensional presentation of all their academic and non-academic achievements.

Keywords: Digital Citizenry, Web Presence, Digital Footprints, Databots, Personal Branding, Internet of Things, Predictive Analytics, Machine Learning, Social Media Manager, Web 2.0

\section{INTRODUCTION}

Traditionally, the term, brands, has been associated with businesses, products, services, or organizations. As technology continues to grow, however, brands can be extended to also include humans. The rise of using Professional Social Networks, such as LinkedIn, is an example of brands extending to humans. As Hood, Robles, and Hopkins [1] mentioned, a surfeit of hiring managers looked at potential job candidates' Social Media profiles, such as Facebook, throughout the process of recruitment and hiring. Personal Branding has been an integral part of marketing since a plethora of companies research their potential employees through their digital presence [1]. Likewise, the value of students' degrees and 
how they are applicable to employers has become an integral discussion among businesses [5]. Because of this, managing one's Digital Footprint has become imperative. A Digital Footprint can show digital traces that have been left by people as they use various services on the internet [2]. Similarly, a person's Digital Footprint can be analyzed to gain insights on individuals [2]. As the job market continuously changes and further shifts toward technology driven methods, it becomes crucial that people realize the importance of their Personal Brand and Digital Footprint as well as the impact that it can have on their career.

The purpose of this research is based on the hypothesis that people with more professional accounts have an increased awareness of their Personal Brand and Digital Footprint. Alternatively, the other part of the hypothesis is that the people who have fewer professional accounts have a decreased awareness of their Personal Brand and Digital Footprint. To test this hypothesis, a survey was conducted. The respondents were scrutinized to gauge their awareness of their Personal Brand, the number of Social Media accounts that they use, the number of Professional Social Network accounts that they utilize, and their willingness to use a technology that would allow them to manage their Personal Brand and Digital Footprint. Furthermore, the survey gathered respondents' inclination to use an application that would allow them to build a Digital Passport to hold their academic and non-academic achievements, experiences, skills, interests, aptitudes, and career highlights to share with potential employers.

In addition to the survey, a literature review was also conducted. From this research, it became apparent that professionalism among students is paramount. As Chretien,
Goldman, Beckman, and Kind [3] noted in their article, It's Your Own Risk: Medical Perspectives on Online Professionalism, differentiating between professional and unprofessional behavior is difficult. While some areas in which to delineate what could be considered as unprofessional are easier to understand, trying to find a balance can be difficult [3].

Additionally, linked to one's personal brand is their Web Presence, particularly in the context of Social Media [4]. The significance of one's Personal Brand is indubitably important since it can have such a high impact on an individual's career [4]. In order to allow students to realize this, an application was conceptualized for them to be able to check their Web Presence as well as Personal Brand and Digital Footprint. Moreover, the students are also able to upload information about themselves such as their resume, portfolio that denotes what they learned, and a video. Another solution for the problem that students face as their Personal Brand and Digital Citizenry becomes scrutinized by potential employers is to also create a space where students have a digital space, or a "vault", for their information and be able to have a Digital Passport. Similar technology, such as Google Docs or Microsoft Dropbox, also use a similar method to save and share files, but the "vault" feature of this application would allow students to have a specific space for their information, which would have extra security features for more sensitive and restricted document files and personal information.

To build a professional Personal Brand and Digital Footprint, adhering to the concept of value, mission, image, and vision is paramount. When posting information about oneself, it is important to weigh the value of the information as well as the mission of this 
data. Similarly, building an image and having a vision is equally as significant since they put an individual's goals into the forefront. The formula based off this is:

$$
\left.f(\text { Personal Brand })=\sum_{t=1}^{\infty} \text { DFP(Image }+ \text { Value }+ \text { Mission }+ \text { Vision }\right)^{t}
$$

Each of these values is fundamental to a person's Personal Brand. The meaning of this formula is that Personal Brand is equal to the sum of an individual's Digital Footprint, which is a conglomeration of image plus value plus mission plus vision.

With the rise of the usage of Databots and deep machine learning in the World Wide Web 2.0, predictive learning has become popular since a plethora of information can be about users based off the online data that Databots recover [6]. However, depending on the information found, it could negatively impact a person since Databots only see facts and not the possible reason for the result. For example, if a person were to post a picture of them going to a restaurant that also had an image of them standing next to a bar, the Databots could see that and make the conclusion that the individual frequents bars, which would harm someone's credibility with potential employers. Due to this, the need to find a solution that allows students to be able to build and manage their Personal Brand and Digital Footprint has become necessary.

\section{METHODS}

In choosing a method of study, a survey was chosen in order to reach the group of respondents that would be using this application. Likewise, the survey approach was chosen because it met the criteria of this project since it needed input from the targeted user group. The study was conducted through Google Forms and dispersing the links through classes at Indiana University Purdue University, Indianapolis where students would take the survey and give feedback. By giving the survey to students, the research was able to include the opinion of the primary users of the application. The survey itself included questions that asked students to opine on their awareness level of their Personal Brand, the number of Social Media accounts, as well as the amount of Professional Social Network, accounts that they had, and their willingness to use an application like the Personal Branding and Digital Citizenry system.

The survey was left open for several weeks. The hope was that, by leaving it open for a longer period of time, more people would be able to participate in the research. The analytics provided by the Google Forms were used to analyze the information that the participants contributed to make the conclusions. The survey itself was split into different sections; each section being applicable to three topics that were being tested. By doing this, the team was able to form a working knowledge of the level of familiarity that the participants had for the topic. For example, the questions, "How much are you aware of the Personal Brand?", was a question that was asked to gauge the level of awareness that participants had of this topic. Additionally, this was asked in order to gain insight into what the general public may or may not know about the subject.

\section{FINDINGS}

The data that was collected from the surveys held a number of multifarious patterns that were found in the process of analyzation. The survey had 55 volunteer participants, 
which enabled the team to gather a surfeit of information that was applicable to the topic.

The primary interest was in determining if people considered themselves a Personal Brand. From the results, which can be seen in Figure 1, the majority of the respondents answered positively, "Yes". 62\% considered themselves a Personal Brand while 38\% did not believe that they were a Personal Brand.

DO YOU CONSIDER YOURSELF A PERSONAL BR

$$
\text { No }
$$

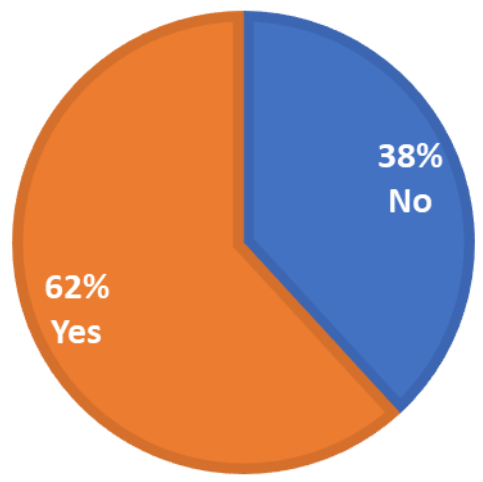

Fig. 1: Do You Consider Yourself A Personal Brand

Another question that was asked was "How much are you aware of the Personal Brand?" This was asked in order to gauge the respondents' level of awareness regarding Personal Brand. The results indicated that $51 \%$ of the respondents answered that they were "Somehow Aware". A small percentile $(23 \%)$ responded that they were "Very Aware". However, 13\% of the individuals who took the survey noted that they were either "Not Sure What My Personal Brand is" or they "Have No Idea". The breakdown of the results can be seen in Figure 2 as it shows a histogram representation of the respondents' answers.

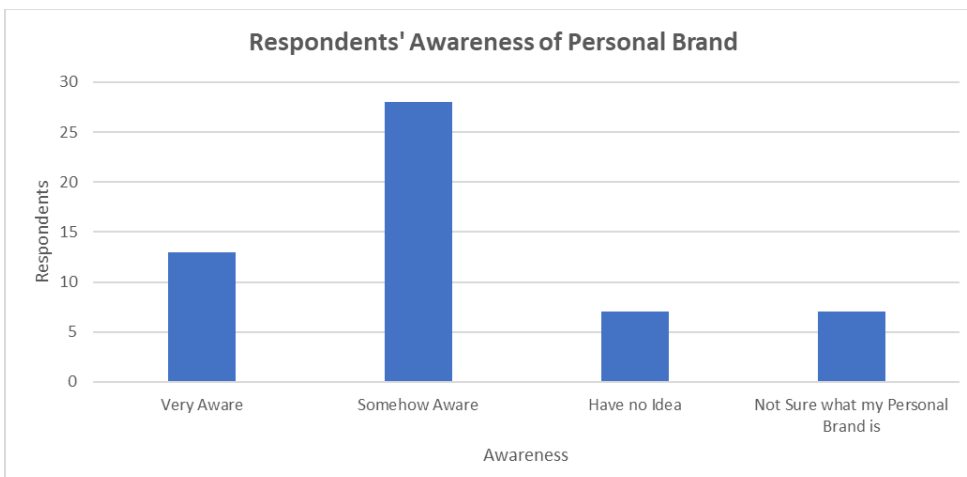

Fig 2: Respondents' Awareness of Personal Brand

Interestingly, when asked regarding the number of Social Media accounts, such as Facebook or Instagram, that the respondents have used in the past or are still using, the majority (53\%) answered that they had fewer than five Social Media accounts. Furthermore, the area with the second most responses was between five, but less than 10 $(33 \%)$. However, the preponderance of individuals (84\%) stated that they had less than five Professional Social Network accounts while very few stated that they had more than five (7\%). From these results, we were able to infer, based on Figure 3, that the number of students who had a greater awareness of their Personal Brand and Digital Footprint had more Professional Social Network accounts than those who are not as aware. 
Respondents Awareness of Personal Brand \& Digital Footprint Compared to Number of Professional and Social Media Accounts

\begin{tabular}{|c|c|c|c|c|c|c|}
\hline \multirow[b]{2}{*}{$\begin{array}{l}\text { Respondents } \\
\text { Awareness of } \\
\text { Personal Brand \& } \\
\text { Digital Footprint }\end{array}$} & \multirow[b]{2}{*}{$\begin{array}{l}\text { Number of Social Media } \\
\text { Accounts }\end{array}$} & \multicolumn{5}{|c|}{ Number of Professional Media Accounts } \\
\hline & & $\begin{array}{r}\text { I have } \\
\text { several } \\
\text { but not } \\
\text { sure how } \\
\text { many }\end{array}$ & $\begin{array}{r}\text { Less } \\
\text { than } 5\end{array}$ & $\begin{array}{r}\text { More } \\
\text { than } 5 \\
\text { less than } \\
10\end{array}$ & $\begin{array}{r}\text { More } \\
\text { than } 10\end{array}$ & None \\
\hline Have no idea & Less than 5 & & $9.09 \%$ & & & $1.82 \%$ \\
\hline \multirow{2}{*}{$\begin{array}{l}\text { Not sure what my } \\
\text { Personal Brand is }\end{array}$} & Less than 5 & & $7.27 \%$ & & & \\
\hline & None & & $1.82 \%$ & & & \\
\hline \multirow[t]{5}{*}{ Somehow aware } & I have several but not sur.. & & $1.82 \%$ & & & \\
\hline & Less than 5 & & $21.82 \%$ & & & \\
\hline & More than 5 less than 10 & $1.82 \%$ & $12.73 \%$ & $5.45 \%$ & & $1.82 \%$ \\
\hline & More than 10 & & & $1.82 \%$ & & \\
\hline & None & & $3.64 \%$ & & & \\
\hline \multirow[t]{4}{*}{ Very aware } & Less than 5 & & $12.73 \%$ & & & \\
\hline & More than 5 less than 10 & & $10.91 \%$ & & & \\
\hline & More than 10 & & & & $3.64 \%$ & \\
\hline & None & & $1.82 \%$ & & & \\
\hline
\end{tabular}

\% of Total Respondents broken down by Number of Professional Media Accounts vs. Respondents Awareness of Personal Brand \& Digital Footprint and Number of Social Media Accounts . Percents are based on the whole table.

Fig. 3: Respondents' Awareness of Personal Brand \& Digital Footprint Compared to Number of Professional and Social Media Accounts Chart

Likelihood to use Application Compared to Awareness of Personal Brand and Digital Footprint

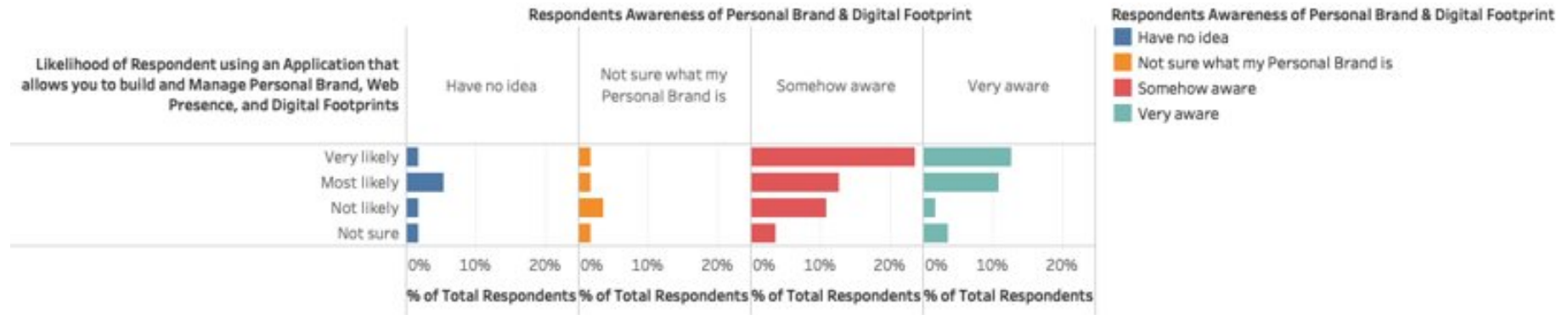

\% of Total Respondents for each Likelihood of Respondent using an Application that allows you to build and Manage Personal Brand, Web Presence, and Digital Footprints broken down by Respondents Awareness of Personal Brand \& Digital Footprint. Color shows details about Respondents Awareness of Personal Brand 8 Digital Footprint. Percents are based on the whole table.

Fig. 4: Likelihood to use Application Compared to Awareness of Personal Brand \& Digital Footprint.

As an effort to study how likely users would be to use an application like the Digital Passport, a question was included about this. Over $70 \%$ of the respondents responded positively that they would be likely to use an application like the Digital Passport as it can be seen in Figure 5.
In addition to looking at Social Media accounts, respondents' willingness to use an application that would allow them to build and/or manage their Personal Brand, Web Presence, and Digital Footprint was also evaluated. Based on these findings, the respondents had an inclination to utilize an application that would allow them to build and manage their Personal Brand as well as other related activities. Of the results, 71\% were positive. From this and comparing the respondents' awareness of their Personal Brand and Digital Footprint, it can be suggested that students who have more inclination toward using our application also have more awareness in these areas as it can be seen in Figure 4. 
are aware of their Personal Brand and Digital Footprints. Based on the results shown in Figure 6, it was noticeable that as a person's awareness level of their Personal Brand and Digital Footprint rose, so did their likelihood of using an application that would allow them to make a Digital Passport Application.

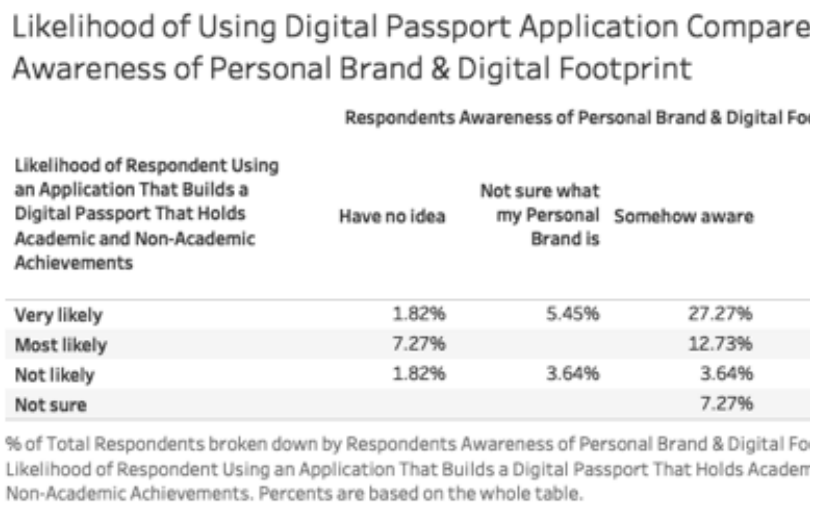

Fig. 6: Likelihood of Using Digital Passport Application Compared to Awareness of Personal Brand \& Digital Footprint

Another question gathered students' opinions regarding whether or not they believed that an application that allows them to store, manage, and share their projects like a Capstone is needed. Based on the answers, $82 \%$ believed that there should be an application like this. To view a visual representation of this data, see Figure 7.

DO YOU BELIEVE AN APPLICATION TO ALLOW STUDENTS TO STORE, MANAGE, AND SHARE THEIR SCHOOL PROJECTS IS NEEDED?

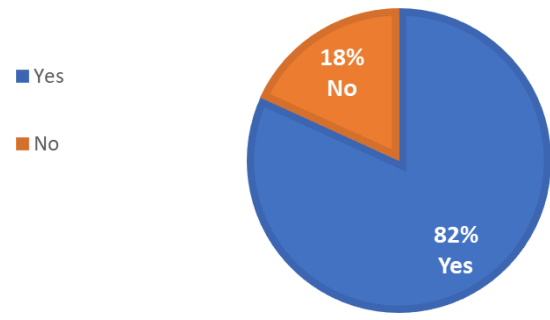

Fig. 7: Do You Believe an Application to Allow Students to Store, Manage, and Share Their School Projects is Needed

\section{SOLUTION}

Based on the research gathered, there appears to be an acute need for an application that allows students to be able to build and manage their Personal Brand, Web Presence, and Digital Footprint. Because of this, the development of the Personal Branding and Digital Citizenry (PBDC) system is important for students and universities. The system provides both schools and professional organization with a Capstone and Career Fair management application that allows the school to schedule and manage secure access to view and rate students' capstone or final course projects. Similarly, the PBDC is also a powerful Personal Branding tool that allows students to develop and promote their own Personal Brand. Students can also measure and manage their career using a Digital Passport to express, share, as well as manage a multi-dimensional presentation of all their academic and non-academic achievements, experiences, skills, interests, aptitudes, and career highlights.

Similarly, another part of the solution is to create a Digital Citizenry tool in addendum to the PBDC system that allows students to become fully aware of their Web Presence and manage, facilitate, and monitor their Social and Professional Networks with a built-in Digital Footprint Analyzer and their own Social Media manager to supervise their Web Presence.

MyLibrary, a personal and smart digital object repository, is another part of the PBDC system that interfaces with the campus' Learning Management Systems. The MyLibrary application enables students to build, deposit, and maintain their own virtual library shelves of their favorited course materials that they wish to save for 
future use. Inside the MyLibrary application, a Digital Vault is part of the system that would be hidden in students' virtual library shelves which would allow them to safeguard and protect their digital assets, private information, and documents. For added security, Blockchain would be added to the Digital Vault.

Moreover, the PBDC solution also offers perpetual efficacy due to its unique nature. The application is built with a combined $360^{\circ}$ approach for students and aspiring professionals to be accountable for their career. Through this, recruiters, admissions, and employers can in turn, accountably attract, manage, retain, and grow talent more efficiently. This can be done by providing best-in-class Personal Branding \& Digital Citizenry management support for students and aspiring career professional, and best-inclass management support for academic admins, career services, recruiters/admission, and employers; both campus and professional organizations will change the way students manage their Personal Brand and careers.

Other notable features of the PBDC is that it would enable students to create a more inclusive portfolio is the built-in Digital Rights Management (DRM), Copyright Tracking with Audit Trail and Version Control, and the ability to hold and manage all types of files. Likewise, students can look at metadata for searching, browsing, and discovery as well as configurable workflows with user roles and permissions. They can also use access-controlled collections with customizable classification and web service interfaces for various types of Learning Management Tools such as Canvas or Blackboard.

\section{CONCLUSION}

As technology continues to grow, the importance of managing one's Personal Brand and Digital Footprint becomes paramount. Students' actions online matter as well as their Web Presence. Previously, brands have been limited to various products or business, but not, brands can encompass humans. The current era is one of technology, which increases the importance of Professional Social Networks and peoples' presence on those networks. Because of this, the survey that was conducted found out that the majority of the respondents had some awareness of their Personal Brand. Additionally, the individuals who had more awareness also appeared to have more Professional Social Network accounts than those who had less awareness of their Personal Brand. Due to these facts, our team concluded that the initial hypothesis that stated that people with more professional accounts have an increased awareness of their Personal Brand and Digital Footprint appeared to be correct based off of the correlations between the data. The need for an application like the PBDC system is becoming more important as the influence of the World Wide Web 2.0 becomes more prevalent in society.

\section{REFERENCES}

[1] K. M. Hood, M. Robles, and C. D. Hopkins. "Personal Branding and Social Media For Students in Today's Competitive Job Market," in The Journal of Research in Business Education, vol. 56, no. 2, Jan. 1, 2014.

https://www.questia.com/library/journal/1P3 -3948508701/personal-branding-and-socialmedia-for-students-in (accessed Apr. 4, 2019).

[2] J. Hinds and A. N. Joinson. "What Demographic Attributes Do Our Digital Footprints Reveal? A Systematic Review." in PLOS ONE, Nov. 2018 [Online]. 
https://journals.plos.org/plosone/article?id=1

0.1371/journal.pone.0207112 (accessed Apr. 4, 2019).

[3] K. C. Chretien, E. F.Goldman, L. Beckman, and T. Kind. 'It's Your Own

Risk: Medical Students' Perspectives on Online Professionalism," in Academic Medicine, Oct. 2010 [Online].

https://www.ncbi.nlm.nih.gov/pubmed/2088 1708 (accessed Apr. 4, 2019).

[4] Y. Kawano, Y. Obu, Y. Kishimoto, T. Yamaguchi, E. Nunohiro, and T. Yonekura. "A Personal Branding for University Students by Practical Use of Social Media," in 15th International Conference on Network-Based Information Systems, Sept. 2012 [Online]. https://ieeexplore.ieee.org/document/635494 1 (accessed Apr. 4, 2019). [5] M. Staton. "The Degree is Doomed." Harvard Business Review. https://hbr.org/2014/01/the-degree-isdoomed (accessed Apr. 4, 2019).

[6] C. O'Dell. "AI, Machine Learning, and the Basics of Predictive Analytics for Process Management." Predictive Analytics World.

https://www.predictiveanalyticsworld.com/p atimes/ai-machine-learning-and-the-basicsof-predictive-analytics-for-processmanagement/9632/ (accessed Apr. 4, 2019). 